\title{
A AQUISIÇÃO DE LEITURA EM CRIANÇAS DO PRIMEIRO CICLO DO ENSINO FUNDAMENTAL É UM DESAFIO AOS PROFESSORES
}

\author{
ACQUIREMENTOF READING IN CHILDREN OF THE FIRST CYCLE OF \\ FUNDAMENTAL EDUCATION IS A CHALLENGE TO TEACHERS
}

Maria de Nazaré Madureira de Souza ${ }^{1}$

RESUMO: O processo de aquisição da aprendizagem da leitura é base crucial para qualquer ação educativa. Ler, compreender, interpretar, decifrar o que leu são elementos primordiais para a ampliação do senso crítico, formação de uma cidadania plena, permitindo assim, a continuação dos estudos inclusão e atuação do indivíduo na sociedade. Ressalta-se, que as crianças ao iniciarem o processo de alfabetização estão impregnadas de uma gama de conhecimentos, que quando usados com eficiência são grandes aliados no processo de ensino e aprendizado da leitura. Afinal, aprender com o que já se conhece, a aprendizagem torna-se mais fácil e eficaz. Sabe-se que os problemas relacionados à leitura no primeiro ciclo do Ensino Fundamental não serão solucionados em curto prazo, pois, faz-se necessário a intervenção e cooperação dos vários sujeitos que estão engajados direta ou indiretamente no processo de ensino. Daí a necessidade de um novo redimensionamento no processo educativo. Buscar novas formas, novos modelos de aplicar a leitura, modernizando metodologias de acordo com a realidade e contemporaneidade da criança proporcionando-lhe um ambiente atrativo, encantador, envolvente que lhe permita querer aprender ler e que ela possa adquirir o gosto e hábito pela leitura.

Palavras- Chave: Leitura. Desafio. Estudante. Professor.

ABSTRACT: The process of acquiring learning to read is a crucial basis for any educational action. Reading, understanding, interpreting, deciphering what you read are essential elements for the expansion of the critical sense, formation of a full citizenship, allowing, thus, the continuation of the inclusion and performance of the individual in society. It is noteworthy that, when children start the literacy process, they are steeped in a range of knowledge, which when used efficiently are great allies in the process of teaching and learning to read. After all, learning from what is already known, learning becomes easier and more effective. It is known that the problems related to reading in the first cycle of Elementary Education will not be solved in the short term, as it is necessary the

1 Graduada em Licenciatura Plena em Pedagogia-Orientação Educacional- UNIFAP, especialista em Psicopedagogia Clínica e Institucional-IBEPEX/FACINTER e mestre em Ciência da Educação pela Universidade Internacional Três Fronteiras/PARAGU. Desenvolveu vários projetos educacionais os mais importantes foram: Combate ao Tabagismo, O lugar do lixo é na Lixeira, Ética e Cidadania, implantou o programa TV Escola na Escola Estadual Vidal de Negreiros no Município de Amapá em 1997. No Colégio Amapaense também implantou o Programa TV Escola em 1998 onde foi coordenadora por vários anos. Atualmente está exercendo suas atividades profissionais na Secretaria da referida Escola, adicionalmente, tem publicado artigo sobre a Importância da Leitura e escrita na vida do Cidadão. E-mail: nazamadu@gmail.com. 
intervention and cooperation of the various subjects who are directly or indirectly engaged in the teaching process. Hence the need for a new dimension in the educational process. Searching for new ways, new models of applying reading, modernizing methodologies according to the reality and contemporaneity of the child, providing him with an attractive, charming, involving environment that allows him to want to learn to read and that he can acquire the taste and habit for reading.

Keywords: Reading. Challenge. Student. Teacher

\section{INTRODUÇÃO}

Leitura é uma atividade que permiti a pessoa conhecer o mundo sem ter a necessidade de sair do meio onde mora. É uma forma de comunicação salutar para o seu desenvolvimento. Pois, ler, constitui um dos saberes mais importantes que uma criança pode adquirir no primeiro ciclo do Ensino Fundamental. A leitura é algo fascinante que oferece momentos de prazer e reflexões.

A pessoa que gosta de ler, tem maiores facilidades de adquirir conhecimentos, boa forma de se expressar, tem conteúdo para boa produção textual, é bem focada nas informações. A prática de ler leva a pessoa ter uma visão panorâmica do mundo e torna ela ser um indivíduo crítico social do meio em que vive.

E nesse sentido, com preocupação de observar a situação do estudante, a sua capacidade de decodificar perfeitamente um texto, mas com muita dificuldade de compreender, interpretar, decifrar aquilo que está lendo em uma escola do Município de Macapá, a autora identificou que pouco estudantes procuram livros para ler, ou que não se preocupam com outras leituras além do livro didático. E que o maior problema de aprendizagem de leitura dos estudantes nos primeiros anos do Ensino Fundamental, estava centrado na dificuldade do processo de alfabetização, principalmente nas atividades de leitura.

Diante disso, a partir do ensino formal, pode-se afirmar que o aprendizado da leitura leva o estudante a desenvolver habilidades de ler e cotidianamente familiarizar-se com essa atividade. Principalmente saber que só através da leitura que ele vai ter acesso a novos conteúdos nas diversas áreas de conhecimento.

Diante dessa exposição, é importante ressaltar que a aquisição de leitura em crianças do primeiro ciclo do Ensino Fundamental é um grande desafio para professor, porque muitos estudantes não gostam de ler enquanto outros se tornam leitores. Esse panorama que se observa em relação ao aprendizado da leitura, revela que existem muitos contrapostos que estudantes e professor enfrentam na busca pelo aprimoramento contínuo da aprendizagem. 
A leitura segundo (Pinheiro et al. 2012) é o exercício mais importante no processo ensino aprendizagem do sujeito, sendo visto como uma prática que possibilita ampliar os limites do próprio conhecimento, por isso as pessoas produzem as suas leituras diversificadamente em diferentes circunstâncias da vida.

Segundo Garcia (2014 p. 36/37)," a comunicação é adquirida, pela maioria das crianças, de forma espontânea e natural e é algo do qual o componente biológico e inato é inegável, posto que, no devir filogenético da espécie humana, a comunicação e a linguagem estão enraizadas a partir das próprias origens da espécie. A leitura, e o cálculo são aprendidos a partir intencionalmente e formal no sistema educacional. Pois, conquistá-los exige um grande esforço, embora isso seja variável e seja inserido nas diferenças humanas"

Diante dessa exposição, surge a questão: Mas afinal, a aquisição de leitura em crianças do primeiro ciclo do Ensino Fundamental é um desafio para o professor? Martins (2016, p.25) ressalta que diante da crise na educação brasileira, muitos educadores "apregoam a necessidade da construção do hábito de ler". Ou seja, isso significa que é preciso criar formas, situações que demonstrem a importância da leitura como prática social constante para os estudantes.

Toda via, o professor é o mediador entre o que a escola tem a oferecer para o desenvolvimento do estudante como leitor, e o que o estudante tem que aprender para que esse desenvolvimento seja significativo. Para isso, e baseado nesse contexto, um dos desafios desta pesquisa é identificar causas que contribuem para a aquisição de aprendizagem ou não, da leitura de estudantes no primeiro ciclo do Ensino Fundamental na escola/campo da rede municipal em Macapá. Dessa forma, no decorrer da pesquisa, a autora cita contribuições a respeito do assunto.

Para Garcia (2014, p. 38),” [...] é necessário elaborar propostas alternativas em que o campo específico das dificuldades de aprendizagem dentro e fora do sistema educacional seja reconhecido e seja reforçada a criação de serviços especializados que permitam melhorar as condições de vida dessas pessoas. É evidente que essa concepção revele a ênfase educativa, mas não nos faz esquecer que a complexidade, vá além do educativo e, por outro lado, apresenta características específicas e requer atenção especializada”.

Dessa forma, escola e professor têm o dever de fornecer a continuidade dos estudos nos anos que se precede um do outro sem prejuízo de defasagem de conteúdo e déficit na aprendizagem da leitura dos estudantes. Embora seja uma tarefa desafiadora, ajudá-lo a apreender a leitura e dotálo de um instrumento de tomada de consciência são fatores cruciais no processo ensino e aprendizagem do indivíduo. 
Em razão disso, no desenvolvimento desta pesquisa evidencia-se a questão desafiadora que o professor encontra para a aquisição da leitura em criança do primeiro ciclo do Ensino Fundamental, evidencia-se também a concepção de aprendizagem da leitura, identificam-se as principais causas das dificuldades que contribuem para a aquisição da aprendizagem da leitura, recomenda-se também, sugestões à Secretaria Municipal de Educação de Macapá para melhorar o ensino e aprendizagem de leitura dos estudantes nesse Município, sendo essas as fundamentações teóricas aqui apresentadas que sustentam este artigo.

\section{DESENVOLVIMENTO}

\section{I OS DESAFIOS DA AQUISIÇÃO DE LEITURA}

A aquisição da aprendizagem da leitura em crianças do primeiro ciclo do Ensino Fundamental continua sendo um desafio constante para o professor em sala de aula atualmente tendo em vista a grande responsabilidade que o assunto requer. Pois, para determinadas pessoas a leitura é um hábito tão incorporado que parece algo natural enquanto para outras não. Entretanto, se pensar como era a forma de ensinar o estudante ler em épocas anteriores verifica-se ainda hoje, ranços dessa prática.

A leitura é a atividade mais importante no processo de ensino, aprendizagem do estudante, embora, sendo visto como uma operação difícil, porém é muito gratificante. Para a autora, a leitura não se limita apenas em livros da escola. Ela diz que todas as formas de leitura são importantes para acessar informações do cotidiano. Pois, é uma atividade que apresenta forte relação com que aconteceu ou está acontecendo nas sociedades e que incentiva o estudante a despertar a curiosidade em descobrir um mundo novo, deixando-o, livre para trilhar seus próprios caminhos.

Piaget ressalta que o estudante evolui de acordo com seu estimular, onde o professor possa buscar mecanismo para que ele consiga desenvolver seu estímulo através da leitura partindo assim do seu conhecimento prévio onde o mesmo passa pelo processo de transformações.

De acordo com Freire (20II, p. 29)

Refiro-me a que a leitura do mundo precede sempre a leitura da palavra e a leitura desta implica a continuidade da leitura daquele. Na proposta a que me referi acima, este movimento do mundo à palavra e da palavra ao mundo está sempre presente. Movimento em que a palavra dita flui do mundo mesmo através da leitura que dela fazemos. De alguma maneira, porém, podemos ir mais longe e dizer que a leitura da palavra não é apenas procedida pela leitura do mundo, mas por uma certa forma de "escrevê-lo" ou de "reescrevê-lo", quer dizer, de transformá-lo através de nossa prática consciente. 
E nesse sentido, cabe ao professor enfrentar os desafios e proporcionar atividades que motivem o estudante criar gosto pela leitura. Que possibilitem desenvolver uma prática construtiva, tornando-se sujeito pensante e ativo diante de sua capacidade. Pois, o exercício permanente da leitura na escola, e fora, é uma atividade essencial para a formação de leitores. E dessa forma, o melhor que uma escola pode oferecer aos estudantes, são atividades atraentes, motivadoras, voltadas para a prática de leitura no seu cotidiano.

Todavia, é importante também, que desde a educação infantil a escola trabalhe com atividades lúdicas que cerquem a diversidade da linguagem oral, organizem conhecimento acerca de gêneros textuais e contextualize o seu uso na sociedade. Desse modo a prática da leitura na escola precisa se assemelhar à prática da leitura fora da escola. Os estudantes precisam saber que lemos por diferentes razões e que não lemos todos os textos da mesma forma.

Ler para os estudantes é uma atividade fundamental e muito importante. Eles merecem que os adultos leiam diariamente, pois ouvindo contos, fábulas, mitos, notícias ou poemas, enquanto ainda não sabem ler oralmente é algo estimulador, que possibilita e motiva o estudante a partir de então, tomar gosto pela leitura e se tornarem bons leitores dentro e fora da escola. Por isso, ler para os estudantes em sala de aula não deve ser uma atividade extra, ou seja, quando sobrar tempo, quando a classe estiver muito agitada ou quando faltaram muitos estudantes no dia. A leitura precisa ocupar horário nobre na sala de aula todos os dias.

Contudo, observa-se que muitos estudantes, não conseguem criar o hábito pela leitura, em toda sua trajetória escolar, talvez porque a escola não tenha e venha cumprindo bem o seu papel enquanto instituição formadora de cidadãos leitores do mundo desde a educação infantil, perpassando pelo Ensino Fundamental até a conclusão do Ensino Médio. Entretanto, percebe-se que muitos estudantes não têm tantas oportunidades, fora da escola, de familiarizar-se com a leitura. Talvez não vejam muitos adultos lendo, talvez ninguém lhes leia livros com frequência. Nesse sentido, a escola não pode compensar as injustiças e as desigualdades sociais que se observa em todo o panorama nacional, mas pode fazer muito para evitar que essas injustiças sejam acirradas em seu interior. Afinal, ajudar o estudante aprender a ler, se interessar pela leitura e criar gosto pala leitura, é o seu papel fundamental na sociedade.

\subsection{CONCEPÇÃO DE APREDIZAGEM DA LEITURA}

Dessa forma, a compreensão e a finalidade da leitura se alteram em consonância com a concepção do hábito de ler internalizado por cada estudante. $O$ ato de ler, nesse sentido é concebido como um processo que além de medir a aquisição do conhecimento, apresenta uma natureza política 
e ideológica, que tem a possibilidade de moldar os sujeitos a agir conforme determinados princípios (ATAIDE 2013).

Desse ponto de vista e nessa mesma concepção (CHIAPPINI, 2005) diz que a leitura é uma arma que pode ser utilizada para dominar, com o pretexto de que se está possibilitando acesso a informações muitas vezes, para justificar ideias anteriores.

Essa concepção crítica de leitura é uma forma necessária para a formação plena do estudante, enquanto ele se torna capaz de entender o significado e operar criativamente um tipo de saber, o seu desempenho intelectual fica cada vez mais singular. O avanço nesse campo de estudo, justifica-se tanto pelas contribuições das Ciências das linguagens, da Psicolinguística e Sociolinguística, quanto pela construção de uma crise da leitura, visto que esta não vinha sendo tratada para fins pragmáticos (BECALLI, 2007).

É importante observar também, que o estudante só tem vontade de ler quando a leitura é livre. Isto é, quando não se obriga toda uma classe à leitura de um mesmo livro, com a justificativa de que tal livro é apropriado para a faixa etária de estudantes dando uma falsa impressão de que o aprendizado acontece igual para todos.

A aprendizagem da leitura na escola deve levar o estudante a descobrir nos textos sua face mais pessoal e prazerosa, sua dimensão mais encantadora e envolvente. $\mathrm{O}$ ato de ler como qualquer aprendizagem requer dedicação. Por isso os estudantes devem ter a oportunidade de encarar o ato de ler como um desafio interessante que abrirá portas, não só para conhecimento, mas também para o entretenimento e a diversão.

A prática da leitura na escola deve se assemelhar à prática da leitura fora da escola. Os estudantes precisam saber que devemos ler por diferentes razões e que não lemos todos os textos da mesma forma. E, nesse sentido, é importância a criança internalizar o hábito de ler no primeiro ciclo do Ensino Fundamental

A partir dessa concepção, a leitura ganha significativa importância no campo do conhecimento, pressupondo o contato com elementos que fazem parte da realidade concreta dos estudantes, que se relacionam entre si e com o mundo. Nessa perspectiva, ler para Freire (2.009, p. II) é compreender uma visão crítica que "não se esgota na descodificação pura da escrita ou da linguagem oral, mas que se antecipa e se alonga na inteligência do mundo".

Soares (2018, p. 22) afirma que o "processo de alfabetização na escola, sofre talvez mais que outra aprendizagem escolar, a marca da discriminação em favor das classes sociais economicamente privilegiadas". Nesse sentido observa-se que na maioria das vezes, a escola valoriza mais a língua 
escrita, pois critica a linguagem oral espontânea por pensar que o estudante de classes privilegiadas tem mais facilidades para se adaptar e desenvolver com rapidez funções tanto da língua escrita quanto ao padrão culto da língua oral.

A partir desse pressuposto, é fundamental que a escola compreenda dois fatores determinantes à leitura: o texto, impresso ou em online que é visto pelos olhos, e aquilo que está por trás dos olhos, que é o conhecimento prévio, independente de classe social, pois um estudante ainda não alfabetizado pode ter as melhores informações a respeito de assunto tratado em sua casa, na sua comunidade, no caminho da escola contido em um pequeno texto.

O conhecimento prévio necessário a aprendizagem da leitura, no entanto, não se resume a classes sociais. O estudante aprende a ler participando de atividades de uso da linguagem oral com pessoas que dominam esse assunto na escola e fora da escola. Ele aprende a ler quando está motivado e julga que pode fazer isso. É difícil um estudante aprender a ler quando se espera dele o fracasso. É difícil também, ele aprender a ler, se não for estimulado e achar finalidade na leitura.

Um dos múltiplos desafios a ser enfrentados pela escola, é o de fazer com que os alunos aprendam a ler corretamente isto é lógico. Pois, a aquisição da leitura é imprescindível para agir com autonomia nas sociedades letradas, e ela provoca uma desvantagem profunda nas pessoas que não conseguiram realizar essa aprendizagem, (SOLÉ, 2008, p. 32).

Entretanto, leitura, deve fazer parte da prática pedagógica no cotidiano escolar. Pois, a aprendizagem da leitura constitui, uma importante ferramenta para o prosseguimento dos estudos. E para isso, a escola deve oferecer além da oportunidade de contato com os livros, o lúdico, para o despertar da atenção do raciocínio, da criatividade e do contato autêntico com a leitura. Deve procurar acompanhar as mudanças referentes à transposição didáticas tendo em vista que o desenvolvimento da leitura necessita de recursos didáticos inovadores que motive, e incentive o estudante a querer a aprender ler desde sua iniciação escolar.

$O$ ingresso do estudante nos primeiros anos de vida escolar, marca definitivamente o vínculo com a vida estudantil. Mais do que aprender determinados conteúdos, o estudante enfrenta desafios de se adaptar a vida escolar, de internalizar o hábito de leitura e a dinâmica de estudos, colocando-se disponível ao conhecimento.

Nesse sentido, é plangente constatar que, ao longo dos anos de escolaridade, crianças que ingressaram no primeiro ano do Ensino Fundamental não chegam ao fim do curso. Ou seja, ao nono ano. E quando chegam, apresentam déficit na carga de conhecimento e habilidades de ler 
compreender e interpretar o que leu, sem a disposição de prosseguir seus estudos ou interessar-se pelo mesmo.

A realidade do ensino na escola/campo no Município de Macapá, demonstra o quanto a intensidade da relação estudante/escola, considerados em seus diversos planos, são determinantes no processo de ensino e aprendizagem. Embora a comiseração de que "no plano metodológico, as linhas mais gerais de ensino tendem a inibir a iniciativa pessoal, os esforços criativos de produção e a autonomia no trabalho escolar (Alencar, 1995, p. 74).

De maneira simples, é preciso que o processo de escolarização contemple o pleno desenvolvimento do estudante. Essa concepção de educação amplia os saberes já incorporados pelos mesmos, fortalece a curiosidade, aguça a expectativa em cada um para que essa busca não se esgote.

Assim, no período atual, é cada vez maior a necessidade de consciência, que na escola, não basta só transmitir informações: é preciso primeiro, formar bons cidadãos leitores, preparados para o exercício da cidadania plena. "É assim que crianças por natureza ativas, e curiosas, podem tornarse cidadãos conscientes, críticas e responsáveis (Chalita, 2004, p. 56)

\subsection{CAUSAS DAS PRINCIPAIS DIFICULDADES QUE CONTRIBUEM PARA A AQUISIÇÃO DE APRENDIZAGEM DA LEITURA NO PRIMEIRO CICLO DO ENSINO FUNDAMENTAL}

As dificuldades de leitura são as mais comuns e são extremamente prejudiciais ao desenvolvimento pleno educacional dos indivíduos, tanto nos resultados, quanto à motivação, à autoestima, ao sucesso profissional. Por isso, no primeiro ciclo do Ensino Fundamental, no processo de alfabetização deve-se identificar as dificuldades de aprendizagem de leitura, buscando acompanhamento de especialistas, novas formas, novos modelos de metodologias com trabalhos diferenciados com as turmas desses estudantes, para que possam avançar no Ensino Fundamental, sem que haja a necessidade de ficarem retidos.

A formação pedagógica do professor e seu conhecimento educacional no processo de ensino, aprendizagem da leitura são cruciais para que se concretize sua função de educador. $O$ professor deve se manter atualizado permanentemente, para exercer as suas funções. Preparado para enfrentar os desafios diários em seu trabalho pedagógico.

E nesse sentido, ao investigar causas de dificuldades de leitura entre as crianças do primeiro ciclo do Ensino Fundamental em uma escola do Município de Macapá, a autora identificou que os estudantes apresentavam dificuldades na aquisição da leitura. Pois, poucos procuram livros para ler, ou que não se preocupam com outras leituras. E que o maior problema de aprendizagem de leitura 
dos estudantes nos primeiros anos do Ensino Fundamental, estava centrado no método, na forma que a professora utilizava para aplicar a leitura em sala de aula com as crianças. O grande número de repetência era recorrente dessas dificuldades. Os estudantes não apresentavam interesses pela leitura, era porque não sabiam ler mesmo. E esse fato agravava o desinteresse dos mesmos, em participar das atividades em sala de aula.

É esse cenário do ensino da leitura em uma escola do município de Macapá que exige novos paradigmas norteadores, para novas práticas, novas metodologias, novo modelo pedagógico para o ensino de Leitura. A estimulação do desenvolvimento das habilidades da leitura abrange um conjunto de relações, que se faz necessária quando o homem se insere socialmente. Marzolla (2016), ao investigar o processo de domínio da leitura entre crianças pertencentes às classes populares, ressalta o quanto é fundamental que se apresente os valores da cultura em que ela se insere no processo educativo.

Vale ressaltar que a dificuldade do aprendizado da leitura não depende apenas do estudante, e sim de toda a sociedade responsável pelo processo de ensino e aprendizagem, como os professores, os pais, gestores, técnicos pedagógicos e a própria instituição escolar. E nesse sentido, é preciso que a escola tenha uma finalidade voltada para o perfil do estudante que deseja formar.

A dificuldade de ensino aprendizagem, pode estar relacionada a problemas que a criança possui. É pertinente indagar inicialmente o seu baixo rendimento, se não corresponde às expectativas do professor e especialistas em educação escolar, o estudante deverá passar por um diagnóstico médico. Esses casos englobam principalmente, as chamadas disfunções cerebrais e, dentro dessas disfunções, tem-se a dificuldade de leitura.

A depressão infantil é um transtorno capaz de comprometer o desenvolvimento da criança, interferindo no seu processo de maturidade psicológica e social (FREIRE, 2003). A depressão na criança e/ou adolescente pode ter início com perda de interesse pelas atividades que habitualmente eram interessantes, manifestando-se como uma espécie de aborrecimento constante diante de tarefas no cotidiano: brincadeiras, esportes, sair com os amigos, etc., além de apatia, e redução significativa da atividade, às vezes pode causar angustia, tristeza e melancolia. Fatores motivadores para o fracasso escolar dos estudantes.

A depressão infantil não se traduz, invariavelmente, por tristeza e outros sintomas típicos. Se trata de um fracasso pessoal e individual que não corresponde à realidade, havendo outros culpados envolvidos. 
A diferença entre os momentos nos quais as crianças podem estar tristes ou aborrecidas com quaisquer fatores vivenciais que as molestem e a depressão verdadeira está, principalmente, no tempo e na motivação para esse sentimento. A depressão infantil tem sido cada vez mais observada devida, em parte, à atualização conceitual e atenção médica crescente sobre esta doença. (FREIRE, 2003).

Para tornar os estudantes bons leitores - para desenvolver, muito mais do que a capacidade de ler, o gosto e o compromisso com a leitura, a escola terá de mobilizá-los internamente, pois aprender a ler (e também ler para aprender) requer esforço. Precisará fazê-los, achar que a leitura é algo interessante é desafiador, algo que, conquistado plenamente, dará autonomia e independência. Precisará torná-los confiantes, condição para poderem se desafiar a "aprender fazendo". Uma prática de leitura que não desperte e cultive o desejo de ler não é uma prática pedagógica eficiente. (PCN's, 2013, p. 44)

Por isso, é necessário que a escola trabalhe leitura dando a chance aos seus estudantes de serem cidadãos críticos e capazes de refletirem. A escola que não lê para seus alunos, não está dando uma boa formação, para que possam ser bons cidadãos/leitores.

Ainda em relação aos Parâmetros Curriculares Nacionais da Língua Portuguesa há um reconhecimento de documento de que as dificuldades de estudantes na resolução de tarefas de leituras obrigam o sistema de ensino, a pensar na necessidade de definir uma nova didática da leitura e da escrita e, em consequência, obrigam a equacionar os modos de formação de professores para o ensino das competências verbais.

Nisto inclui-se incentivar uma enorme variedade de tarefas para assim se poder ir ao encontro dos diferentes estilos cognitivos presentes na sala de aula. Evidentemente essa diversidade precisa ser submetida a uma programação racional e sistemática orientada por pressupostos de natureza curricular e de desenvolvimento da linguagem.

Geralmente os Parâmetros informam que:

O professor deve ser visto como um facilitador no processo de busca de conhecimento por parte do aluno. Cabe ao professor organizar e coordenar as situações de aprendizagem, adaptando suas ações às características individuais dos alunos, para desenvolver suas capacidades e habilidades intelectuais para leitura. (2013, p. 40)

Exatamente neste ponto, reside a chance de o estudante conquistar resultados mais positivos no processo de alfabetização. O professor consciencioso não medirá esforços para proporcionar ao estudante a necessária instrução, diversificando sempre as metodologias que utiliza. 
As dificuldades e problemas de aprendizagem podem não estar só na criança e sim, em seu ambiente, como na família ou na própria escola. Algumas vezes a queixa do rendimento escolar não expressa uma deficiência da criança e sim uma inadequação das propostas educacionais. É preciso que se mude o enfoque quando uma criança não vai bem na escola, pois a justificativa é que se trata de um fracasso pessoal e individual que não corresponde à realidade, havendo outros culpados envolvidos. Portanto, o pouco acesso à leitura, traz graves consequência para a formação intelectual do estudante no primeiro ciclo do Ensino Fundamental, comprometendo assim sua carreira futura nos níveis posteriores da educação formal.

De acordo com Marzolla (2016) a prática da leitura, entre as classes populares, deve ser oportunizada conforme se apresenta a leitura de mundo, que se vivenciam em suas relações sociais, nesse caso, a escola deve desenvolver estratégias de ensino que possibilitem a criança se apropriar das situações concretas e discernir a realidade, superando o caráter mecânico da leitura.

Pois, é na escola que deve acontecer verdadeiramente a descoberta da leitura pelos estudantes, mesmo sendo de classes populares. Pois, a aprendizagem escolar constitui-se em um direito de igualdade, preconizado pela Constituição Brasileira. E quando a criança que frequenta a escola não obtém sucesso, ou aprovação escolar, ela não teve seu direito mais precioso assegurado.

\section{SUGESTÕES DE DINÂMICAS DE SOCIALIZAÇÃO QUE VENHAM IMPACTAR O ENSINO DA LEITURA NOS ESTUDANTES DO PRIMEIRO CICLO DO ENSINO FUNDAMENTAL NO MUNICÍPIO DE MACAPÁ}

\section{Valorização do profissional da educação}

Para que as dificuldades de ensino e aprendizagem de leitura dos estudantes, sejam superadas, faz-se necessário a existência de políticas públicas com propostas pedagógicas/administrativas inovadoras que incorpore eixos norteadores do processo ensino-aprendizagem nas Escolas do Município de Macapá.

A profissão do professor geralmente, ainda é muito desvalorizada. E isso é um grande empecilho para que consigam melhorias significativas no resultado da educação pública, sobretudo na educação básica. E nesse sentido, observa-se que educadores também estão insatisfeitos com a formação inicial, especialmente, na prática da profissão na Educação Básica.

Eles, querem ser mais ouvidos na formulação de políticas educacionais e sentem que a Secretaria Municipal está muito distante da realidade da escola. 
Não é interessante oferecer um treinamento como se o profissional fosse vazio de conhecimento e sem potencial, mas sim, reconhecer os pontos fortes e trabalhar nos pontos tímidos a serem desenvolvidos. O professor deve sentir que a Secretaria é parceira e juntos estão trabalhando para alavancar principalmente os bons resultados de aprendizagem e a permanência dos estudantes na escola.

\section{O aperfeiçoamento contínuo do profissional da educação.}

Boa parte da formação contínua oferecida pela Secretaria Municipal de Educação no Município de Macapá, na maioria das vezes, não atende às necessidades do dia a dia na sala de aula. O sucesso da formação contínua para professor precisa ser alinhado com outros elementos fundamentais como:

- Melhoria salarial;

- Dedicação exclusiva para que fique em horário integral numa única escola;

- Ser líder em sala de aula;

- Ter autoridade em sala de aula;

- Conquistar a empatia dos estudantes;

- Manter seus estudantes entusiasmados para a aprendizagem;

- Estar em constante aperfeiçoamento profissional;

- Estar atualizado com a Lei de Diretrizes e Base da Educação Brasileira

- Ter visão de futuro;

- Ser consciente do papel que ocupa;

- Ter acesso as novas tecnologias;

- Garantir o número de estudante por turma regulamentado pela Lei que preconiza esse direito;

\section{Aperfeiçoamento contínuo das competências do Coordenador Pedagógico}

O coordenador pedagógico é responsável em atuar com o grupo de educadores coordenando e promovendo reflexão no sentido da construção de uma competência docente coletiva e a esse profissional, são atribuídos importantes funções, incluindo como deve se relacionar com direção, corpos discente e docente, e pais/familiares dos estudantes.

Diante disso, é muito importante que o coordenador pedagógico

- Tenha gratificação correspondente ao cargo que lhe compete;

- Seja empático com toda a equipe escolar;

- Acompanhe dia a dia o fazer didático/pedagógico dos professores, (metodologia, material didático e avaliação); 
- Deia apoio pedagógico a sua equipe

- Esteja em constante aperfeiçoamento profissional;

- Esteja atualizado com a Lei de Diretrizes e Base da Educação Brasileira

- Seja líder da equipe de trabalho;

- Tenha visão de futuro;

- Busque a melhor solução para resolver problema, tenha causas pedagógicas, familiares ou sociais.

- Seja consciente do papel que ocupa.

\section{Aperfeiçoamento contínuo das competências do Gestor escolar}

Ao gestor, não basta só competência, é necessário ter habilidade política administrativa e humana para obter sucesso nas tarefas planejadas. É preciso conhecer bem a equipe que vai dirigir, ter coragem para fazer escolhas, mudanças, definir metas, aproveitar brechas, criar espaços e fazer parcerias com a equipe escolar/familiares dos estudantes.

Diante disso, é muito importante que o gestor

- Tenha gratificação correspondente ao cargo que lhe compete;

- Esteja em constante aperfeiçoamento profissional;

- Conheça a Lei de Diretrizes e Base da Educação Brasileira

- Tenha menos interferência do sistema vigente;

- Seja líder de sua equipe de trabalho;

- Tenha os familiares dos estudantes como parceiras da escola;

- Tenha visão de futuro;

- Seja consciente do papel que ocupa;

- Traga a família pra na escola quando precisar;

\section{Família}

A família é a instituição de primeiro contato do indivíduo com a sociedade, é a partir desse contato que se constrói as primeiras relações afetivas, sociais e cognitivas. O papel da escola irá se encarregar do processo educativo e na preparação do educando para sua inserção na sociedade. E para tanto, a escola deve estar preparada para as mudanças que a sociedade, em especial a família, tem sofrido ao longo dos tempos. 
Quando a família participa da educação de seus filhos, eles podem ter um melhor rendimento na escola, despertando o interesse e a curiosidade. A integração família e escola é um importante recurso para a melhoria na aprendizagem da criança.

Diante disso, é muito importante que escola e família estejam em consonância em alcançar os mesmos objetivos, o ensino aprendizagem do estudante.

E para isso é necessário que a família:

- Cumpra o seu papel em dar apoio aos professores de seus filhos;

- Participe das reuniões na escola;

- Deia apoio aos professores a respeito da melhoria do ensino aprendizagem do estudante;

- Esteja sempre em contato com a (coordenação pedagógica) em busca de informações do estudante;

- Que participe de modo ativo na vida escolar dos filhos;

- Esteja aberta para o diálogo com toda equipe escolar;

\section{Estudante}

Cada escola possui suas próprias regras junto a sua equipe, e isso envolve também os estudantes, e às vezes pode parecer ser muito chato. Muitos estudantes chegam a se sentir oprimidos e outros até ofendidos ao se depararem com determinas exigências da escola. Entretanto, crianças e adolescentes têm direitos e deveres perante a escola e estatuto. E, diante disso, é preciso que a escola informe a estudantes que eles:

- Tem direito de igualdade de condições para o acesso e permanência na escola;

- Tem direito de ser respeitado por seus educadores;

- Direito de contestar critérios de avaliação;

- Direito de organização e de participação em entidades estudantis;

- Acesso à escola pública e gratuita próxima de sua residência.

\section{Os deveres dos estudantes:}

- Respeitar as autoridades da escola;

- Ser pontual e não chegar atrasado as aulas, caso contrário poderá receber uma advertência;

- Utilizar o uniforme corretamente;

- Manter seu material de estudos organizados e tarefas da escola realizadas; 
- Cooperar para a conservação do patrimônio e dos móveis da escola;

- Ser disciplinado e evitar bagunça ou desordem na entrada, saída e intervalos;

- Permanecer na sala de aula até que seja liberado;

- Aproveitar a oportunidade oferecida.

\section{CONCLUSÃO}

A intenção dessa pesquisa, foi trazer a luz do pensamento da autora, o quanto a leitura permeia um expediente palpitante e revelador nas evoluções ou regressões da aprendizagem do saber ler, que o processo de desenvolvimento escolar/educacional é sistêmico e que vários fatores afetam a dinâmica do ensino aprendizagem da leitura dentro desse desenvolvimento.

De acordo com as conclusões obtidas mediante a pesquisa desenvolvida com base no tema a Aquisição de Leitura em Crianças do Primeiro Ciclo do Ensino Fundamental é um Desafio aos Professores em uma escola no Município de Macapá/AP, observou-se que a forma de aplicar a leitura ofertado pelos educadores na escola campo, necessita de um novo redimensionamento no processo educativo. Buscar novas formas, novo modelo de aplicar a leitura, modernizando metodologias de acordo com a realidade e contemporaneidade da criança que permita um ambiente atrativo onde ela possa adquirir e internalizar o hábito e gosto pela leitura de forma prazerosa.

A observação da prática pedagógica das professoras do primeiro ciclo do Ensino Fundamental possibilitou o contato direto com os possíveis espaços de atuação do professor. Nessa observação verificou-se não somente uma prática em sala de aula, mas também mostrou que o processo de leitura é conduzido tradicionalmente, pois embora as professoras busquem se esforçar para obter bons resultados, sua metodologia precisa de novas formas, precisa de novos modelos de aplicar a leitura em sala de aula. O professor é o maior responsável pela formação de bons leitores, e para tanto, deve esteja aberto as mudanças que venham se adaptar à realidade do estudante.

O processo de aquisição pela leitura e o hábito de ler, são bases para qualquer ação educativa. Com isso faz-se evidente a necessidade de se promover ações pedagógicas que tenham como ponto culminante a priorização da leitura enquanto elemento primordial de desenvolvimento do senso crítico do educando, buscando com isso, mecanismos que permitam a inclusão e atuação do indivíduo na sociedade.

E nesse sentido, as observações realizadas na aquisição de leitura em crianças do primeiro ciclo do Ensino Fundamental na escola/campo evidenciou-se que as professoras mantêm uma concepção limitada direcionada a leitura, ou seja, pensam na aprendizagem como um trabalho de 
pura codificação de símbolos e signos, não expandindo suas percepções a ponto de observarem para o fato que essa prática é sobretudo pessoal e social, uma vez que considera as experiências individuais dos estudantes e convivência com o meio onde vive.

Quanto aos objetivos específicos, identificou-se que as professoras não atenderam satisfatoriamente a pesquisa, no que se refere às sequências didáticas. Durante a observação de suas aulas, verificou-se que não houve adequação do tempo para a realização e a sequenciação das atividades de leitura, e não ocorreu uma ordenação das atividades que permitisse o interesse dos estudantes em fazê-las. Ademais, as aulas não tinham articulação entre si e não era destinado tempo suficiente para a aplicação da leitura. As professoras observadas, não pareceram ter planejado suas aulas com metodologias adequadas para superar as dificuldades e garantir a aprendizagem de leitura dos estudantes.

Finalmente, durante a realização da pesquisa, constatou-se que a aplicabilidade do ensino da leitura entre os estudantes do primeiro ciclo do Ensino Fundamental na escola/campo necessita de novas formas, novo modelo metodológico, recursos didáticos diferenciados e compartilhamento de ideias entre os professores e coordenação pedagógica para que o processo de ensino, aprendizagem da leitura de seus estudantes se torne momentos de prazer e satisfação. Essa realidade foi constatada tanto pelas entrevistas com os professore e coordenadores pedagógicos quanto pela observação feita in "locus".

\section{RECOMENDAÇÕES}

Recomenda-se, que a Secretaria Municipal de Educação de Macapá promova cursos de atualização profissional aos professores do primeiro ciclo do Ensino Fundamental onde eles possam alinhar seus planos de aula de acordo com as novas tendências do presente, pautados pela interatividade. Alinhar novas metodologias, utilizando a eficiência da sala de aula invertida. Incluir games e brincadeiras no processo pedagógico. Criar estratégias diferenciadas para atrair a atenção do estudante. Promover também a integração entre a sociedade e a escola com a criação de projetos educacionais. Desenvolver ações efetivas que permitam ajudar os estudantes a desenvolver habilidades de transferência de conhecimento. Que as coordenadoras pedagógicas das escolas, também façam parte dessa formação, para que procedam acompanhamento e alinhamento diariamente aos professores na mesma linha de pensamento. Que a equipe escolar busque parcerias constantes com as famílias dos estudantes. 


\section{REFERÊNCIAS}

AGOSTINE, Michele Zwirtes. O gestor escolar e suas ações frente à gestão. Repositorio.ufsm 2010. Disponível em $<$ https://repositorio.ufsm.br/bitstream/handle

/I/r2135/TCCE_GE_EaD_2010_AGOSTINI_MICHELI.pdf?sequence $=\mathrm{I} \&$ isAllowed $=\mathbf{y}>$ Acesso dia 30 jan 2021.

BRASIL, Secretaria de Educação Fundamental. Parâmetros Curriculares Nacionais: Língua Portuguesa. 2 Ed. Brasília: MEC/SEF, 2013.

BUNZEM, Silvio A. Letramento e alfabetização: Recursos e métodos de aprendizagem. São Paulo: Cortez, 2015.

DHOME, Vãnia. Ludicidade na alfabetização: Aspectos didáticos e metodológicos. São Paulo: Moderna, 2013.

FERREIRO, Emilia. Os Processos da Leitura e da Escrita: Novas Perspectivas. Porto Alegre: Artes Médicas, 2013.

FREIRE, Paulo. A Importância do Ato de Ler: Em Três Artigos Que se Completam. 48 $8^{\mathrm{a}}$ Ed. São Paulo: Cortez, 2013.

GARCIA, Ana Maria de Oliveira (org.). Leitura na Escola Primária Brasileira: Alguns Elementos Históricos. Belo Horizonte: UFMG, 2014.

KRIEGL, Danton S. O Aprendizado da Leitura. $5^{\text {a }}$ Ed. São Paulo: Martins Fontes, 2015.

MARTINS, Maria Helena. O que é Leitura. 2ª ed. São Paulo: Brasiliense, 2016.

MARTINS, Maria da Graças Maia. Dificuldade da leitura e escrita nas séries iniciais do ensino fundamental. Dspace.bc.uepb.edu $2014 . \quad$ Disponível <https://dspace.bc.uepb.edu.br/jspui/bitstream/123456789/558I/I/PDF\%20\%20Maria\%C3\%A7as\% 20Maia\%2oMartins.pdf> Acesso dia 21.jan. 2021.

MARZOLLA, Silvio A. Leitura e escrita na escola: Aspectos metodológicos e pedagógicos. Porto Alegre: Mediação, 2016.

NUNES, Welliton A. Alfabetização e letramento: processos e metodologias. Rio de Janeiro: EDURJ, 2013.

OLIVEIRA, Ana Beatriz. Escrita e leitura nas séries iniciais. Rio de Janeiro: EDURJ, 2014.

PEÇANHA, A. G. Teoria e prática em psicomotricidade. Curitiba: G.P de Almeida, 2015.

POLITY, E. Dificuldade de aprendizagem e família: construindo novas narrativas. São Paulo: vetor 2011. 
RIBEIRO, Leonardo S. Letramento e alfabetização. 2 Ed. São Paulo: Moderna, 2013.

ROJO, E.A.; BATISTA, S, A. Leitura e escrita. São Paulo: EDUSP, 2013.

SANTOS, Maria Helena. Unidade de Leitura - Trilogia Pedagógica. Campinas, SP: Autores Associados, 2013.

VAL, S. Costa. O processo de alfabetização no ensino fundamental. Rio de Janeiro: EDURJ, 2013.

SUSSUARANA, Lívia; BEZERRA, Michelle Batista. Avaliação da produção escrita e desenvolvimento de sequências didáticas. Disponível em: <http://www.fcc.org.br /pesquisa/publicacoes/eae/arquivos/r6II/r6II.pdf > Acesso dia 04 fev 202I.

VEIGAS, Amanda. Entenda qual é o papel do aluno dentro da sala de aula. Somospar 2018. Disponível em: < https://www.somospar.com.br/entenda-qual-e-o-papel-do-aluno-dentro-da-salade-aula/> Acesso dia 02 fev 2021.

RIBEIRO, Mônica Alves, CALDEIRA, Poliane Martins Quinto et al. Escola e família: uma aproximação necessária. Multivix.edu 2018. Disponível em 〈https://multivix.edu.br/wpcontent/uploads/2018/o7/revista-espaco-academico-vo5-noI-artigo-o6.pdf > Acesso dia 30 jan 2021. 